\title{
Three Novel Zinc(II) Sulfonate-Phosphonates with Tetranuclear or Hexanuclear Cluster Units
}

Zi-Yi Du, Hai-Bin Xu and Jiang-Gao Mao*

\section{Supporting Information}

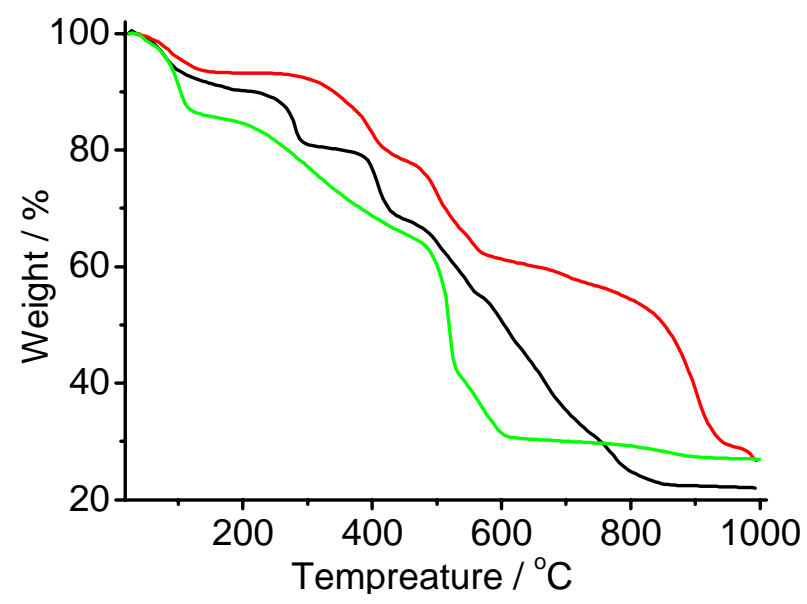

Figure S1. TGA curves of compounds 1 (black); 2 (red) and $\mathbf{3}$ (green). 


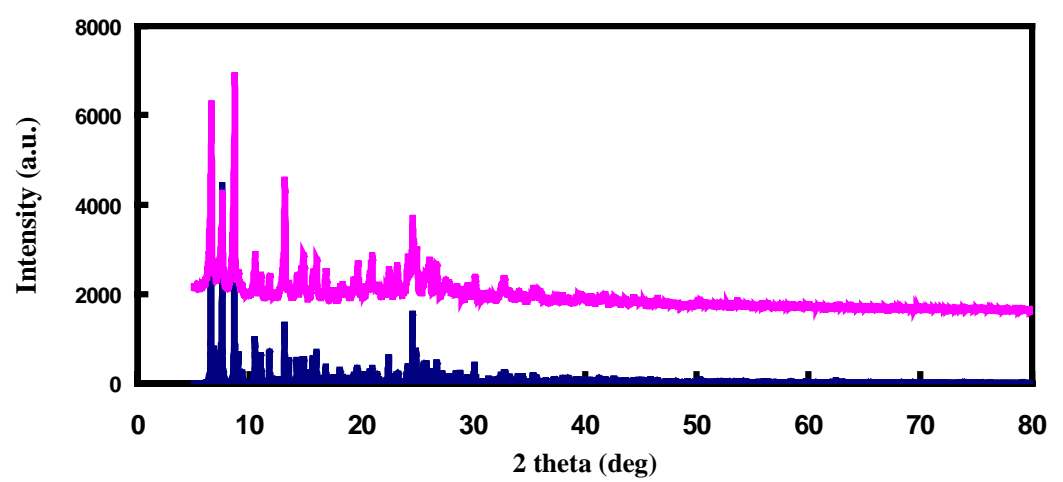

(a)

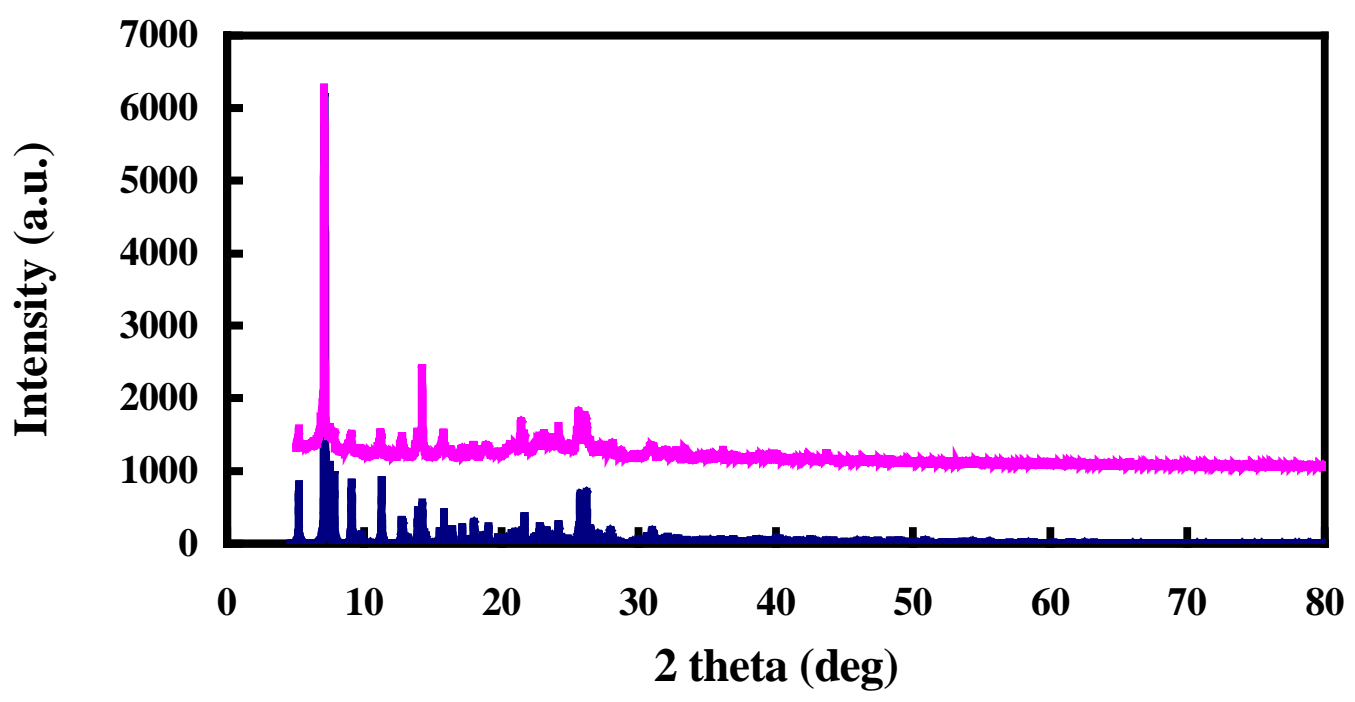

(b)

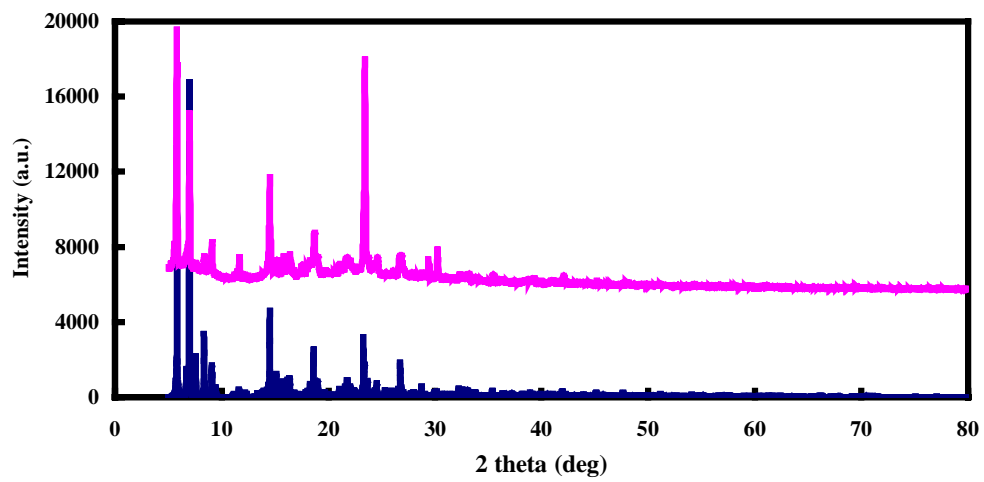

(c)

Figure S2. Simulated (black curves) and experimental (pink curves) XRD powder patterns for compounds 1 (a), 2 (b) and 3 (c). 